\title{
Performance e engajamento político pela paz
}

\author{
Margarida Gandara Rauen
}

... libelos enunciados o tempo todo até nos rótulos... potentes e pós-potentes passam julgamento enquanto oslas endereçados/as os recebem e se curvam ou andam ... andam ... andam muito ...

ando-brinco entre a sentença e a sátira ... sem perder o rosto nos cem mil dois mil(höes) infinitos estilhaços

lembro a libélula cor metálica e também os seixos mais ao fundo

vou buscar mas a retina engana:

faltam a mira aborígene e o ângulo compensado ...

atitude desconstrutiva entende a literatura, a leitura e a escrita como atos políticos e subversivos em si mesmos. Mas será que basta performar [sic.] para transformar ou causar impacto? A performance pode ser como uma flecha equivocada? As dualidades de "libelos...", diferente de uma epígrafe e em desvio a um parágrafo norteador cartesiano, acabam exacerbando as contradições. Processos recepcionais não são tão evidentes quanto um alvo.
Ao iniciar um texto cujo título denuncia o desejo de tratar da relação de artistas com questōes de suas épocas, minhas primeiras linhas estão divididas entre tese/antítese, masculino/feminino, palavra/imagem, urbe/natureza, etc. Entre tantos opostos binários e a irônica certeza de que até este centro textual ou lugar discursivo desconstrutor também é ilusório, encontram-se as inúmeras categorias de performance descritas por Schechner (1977) e, mais recentemente, a taxonomia de Mckenzie (2001), com seus três paradigmas da performance, denominados cultural, organizacional e tecnológico, abrangendo todos os tipos de atividades humanas. Me interessa, aqui, encaminhar algumas reflexões sobre o cenário da performance politicamente engajada, destacando-se a cultural. ${ }^{1}$

Pode-se afirmar, com tranqüilidade, que a constante mutação da arte da performance resulta de seu enfoque iconoclasta: "A história da arte da performance no século XX é a história de um meio permissivo e aberto com infindáveis variáveis, executada por artistas impacientes

Margarida Gandara Rauen é professora da Faculdade de Artes do Paraná (FAP) e da Unicentro, dramaturga e diretora.

1 Performance Cultural, segundo Mckenzie, engloba tudo que, ao longo da história, está ligado ao teatro, à música, à dança, ao cinema, aos rituais, às manifestações folclóricas, às interações sociais, à comunicação não-verbal e à arte da performance (performance art.). O termo está institucionalizado e é usado para denominar programas de pós-graduação, como um Mestrado na Universidade de Bristol (ver <www.bris.ac.uk/drama/postgrad/macp.html>). 
com as limitações das formas artísticas mais arraigadas" (Goldberg, 1988, p.9). Essas infindáveis variáveis foram amplamente registradas por Loeffler \& Tong (1980), Glusberg (1987), Gray (1993) e, já no contexto brasileiro, por Cohen (1987).

Pelo viés das diferenças entre arte modernista e pós-modernista, Auslander, ao discutir teóricos como Fredric Jameson e Hal Foster, argumenta que a resistência mais notável da arte pós-moderna continua sendo contra as formas de representação em si e não apenas contra questões políticas. Na última década, têm chamado bastante atenção as transformações pelas quais a presença performática passou com o advento da hipermediação dos produtos culturais através das redes de computador e informação. Mckenzie afirma que a digitalização da presença foi a mais profunda mudança ocorrida no limiar do século XXI. Cohen, nos últimos trabalhos, não só realizou performances em rede, como refletiu sobre esse assunto num contexto brasileiro: "A produção cênica contemporânea no Brasil, incluindo-se as expressões da performance, das artes visuais, do teatro e das recentes categorizações de Arte e Tecnologia, demarca um constante dialogismo entre o uso de novos suportes - com a apropriação de redes telemáticas ...” (Cohen, 2003, p. 117).
Processos estéticos e tecnológicos à parte, as histórias do teatro e da arte da performance mostram que os temas de diferenças de classe, etnias, gênero e sexualidade também foram tratados com freqüência durante todo o século XX (cf. Carlson, 1996; Montano, 2000). Muito além do teatro político de Piscator, do teatro dialético de Bertolt Brecht, do teatro da crueldade de Antonin Artaud, pós Living Theater, ${ }^{2}$ outras vertentes se desenvolveram e foram objeto de estudo. ${ }^{3}$

Reinelt \& Roach (1992), numa antologia organizada conforme as correntes críticas de estudos culturais, semiótica, desconstrução, feminismo, história, historiografia, hermenêutica e psicanálise, apresentam diversos artigos sobre os rumos da cena com teor explicitamente político. Destaca-se uma seção intitulada "Depois de Marx," e assuntos tão amplos quanto historicização, guerra fria, política do jazz, L.S.D., McCarthy e AIDS.

Elam Jr. (1997), aplicando uma leitura antropológica de rituais (esp. via Victor Turner), revisa montagens do Teatro Campesino de Luiz Valdez e do Black Revolutionary Theatre, de Amiri Baraka, cobrindo o período entre 1965 a 1971. Ao comentar a produção de Valdez e Baraka, Elam conclui que, apesar da forte especificidade de época, os dois artistas permane-

2 Nos Estados Unidos, verifica-se uma grande produção do teatro de esquerda no século XX, como o The Group Theatre, o Living Newspaper, o Mercury Theatre, de Orson Welles e outros de base sindical e agitprop (ver Denning, apud Carvalho, 2004).

3 É importante lembrar que a questão da construção da imagem ficcional a partir do pressuposto de que ela não é um espelho da vida, mas uma representação dela, já ocupava os formalistas russos desde a década de 20 do século XX (esp. Victor Shklovsky, Boris Tomashevsky e Boris Eichenbaum). A idéia de desfamiliarização de Shklovsky foi uma das mais atraentes para os estruturalistas da década de 50 e 60, como os exilados Roman Jakobson (Praga) que acaba nos EUA, junto com René Wellek, grande mentor do movimento de Nova Crítica (New Criticism). Na Alemanha, a influência passa para a Escola de Frankfurt em Walter Benjamin, Herbert Marcuse e Theodor Adorno. Finalmente chegando ao teatro, o distanciamento ou efeito- $\mathrm{V}$ de Bertolt Brecht é uma das expressōes do conceito russo de desfamiliarização; com Brecht, tornar o real estranho na dramaturgia e na cena é posto a serviço de sensibilizar o público criticamente para a dimensão ideológica daquilo que é entendido como real. 
cem como valiosas referências de arte engajada na transformação social e nas mentalidades do público.

Cohen-Cruz (1998), num escopo mundial, mostra as nuances culturais da performance engajada fora dos palcos e/ou espaços cênicos convencionais. Os autores convidados (Richard Schechner inclusive) abordam temas diversos: Tolstoi e a Revolução Russa de 1917, conquistas de espaço em contexto de pós-colonização no Quênia dos anos 70, dilemas de refugiados na Tailândia, xenofobia e racismo nos Estados Unidos, trabalhos do Exército Vermelho da China, as reivindicações do Greenpeace pela natureza, o teatro invisível de Augusto Boal e as manifestações de rua de grupos homossexuais, entre outros.

Nessa bibliografia selecionada, sobre a diversidade de enfoques da performance cultural, percebe-se, entre os autores que oferecem comentários sobre a eficácia social ou o impacto de trabalhos engajados com processos de transformação política, um campo bastante polêmico. Um primeiro aspecto é o do olhar a partir do qual a performance é construída. O problema de ponto de vista, de que a percepção autoral desenha uma representação, às vezes equivocada, também é comentado por Chadwick (1997), ao considerar a arte da performance um dos campos da expressão radical utilizado pelas feministas para atingir grandes públicos fora das casas convencionais de entretenimento, teatro e shows.

Segundo Chadwick, grande parte da produção Norte-Americana e Européia de autoria feminina e sobre mulheres é criticada por refletir, autobiograficamente, uma psicologia da mulher burguesa branca, ao invés de lidar com problemas amplos, situando a mulher como sujeito social e aprofundando temas de opressão política, cultural e sexual. Também os livros de referência destacam a mulher branca. A antologia de Grosenick (2001) é um bom exemplo, por abranger artistas visuais e de arte da performance. Entre 93 mulheres de todo o mundo, encontramos menos de dez não-brancas. Con- sideradas as questôes de falta de oportunidades iguais, os limites das diversas ditaduras do mundo sobre a liberdade de expressão ainda nos últimos cinqüenta anos, os eventuais critérios elitistas e/ou discriminatórios de curadorias, a situação apontada por Chadwick claramente se relaciona com o olhar crítico de quem percebe sujeitos excluídos da produção e das reflexões artísticas.

Em se tratando da autobiografia, no entanto, um extremo interessante está na convicção de uma mulher bastante famosa, que acredita não haver certos tipos de opressão. Trata-se de um depoimento surpreendente da iugoslava Marina Abramovic':

[...] a posição da mulher na Iugoslávia é muito forte. Essa é a razão pela qual eu jamais me interessei por feminismo, porque minha mãe governava tudo. $\mathrm{E}$ as mulheres têm a possibilidade de construir o novo país comunista, de estar envolvidas em todos os níveis de desenvolvimento [...] Então eu sempre senti que você pode fazer qualquer coisa que desejar, não importa se você é homem ou mulher. Nunca me senti reprimida, nunca senti que as mulheres fossem reprimidas (Bernstein, 2003, p. 139-40).

Isso não define, porém, a ausência de engajamento político com outras causas. Na performance Communist Body - Fascist Body (realizada em 30 de novembro de 1979) e descrita por Grosenick (2001, p. 18), Marina Abramovic' e seu então parceiro Ulay convidaram os amigos para uma festa de aniversário em seu apartamento. As pessoas encontraram o casal dormindo sobre um colchão, ao lado de duas mesas onde estavam servidos champanhe e caviar, junto com suas certidóes de nascimento. A de Marina foi carimbada com uma estrela vermelha, e a de Ulay com uma suástica. O objetivo da performance era justapor duas biografias marcadas por ditaduras. Esse aniversário com teor político não constitui um ação performática de grande impacto porque, obviamente, 
atinge um público pouco numeroso. Isso, no entanto, não torna a performance ineficaz no seu contexto. Existem tipos e graus de eficácia e engajamento, na mesma medida em que há tipos de opção estética e ideológica. Sendo assim, a questão da eficácia social de uma proposta engajada não deve ser discutida apenas a partir de critérios universais e/ou de arte para consumo e mercado.

As discussões sobre eficácia costumam endereçar trabalhos específicos, mas muitos artistas já têm cerca de 50 anos de militância. É o caso de Yoko Ono, uma das fundadoras do Grupo Fluxus e também pioneira das performances sobre gênero e etnia: "O estudo de sua própria condição sócio-cultural gerou trabalhos que tocam no problema da presença física e da observação, superação e desestabilização de limites ... A co-responsabilidade do público é testada através de possibilidades de participação e intervenção" (Grosenick, 2001, p. 407).

Nem sempre a performance cultural engajada objetiva a transformação imediata do $s t a-$ tus quo, podendo estar restrita à contemplação e à reflexão. Quando eficácia é entendida no sentido da alteração do comportamento sóciopolítico em grande escala, porém, configura-se o desafio da ação em campo. Dificilmente uma pessoa, hoje, não estará conscientizada sobre a gravidade de nossos problemas de delinqüência, violência e doenças. Entre essa conscientização e o encaminhamento de mudanças, contudo, há um longo caminho a percorrer na sociedade, em suas instituiçôes governamentais e civis, e no contexto acadêmico onde está situada a prática do/da artista/pesquisador(a)/docente. ${ }^{4}$
Além dos currículos defasados e a falta de integração entre a sala de aula ou ensaio e o campo, onde efetivamente se pesquisa e realiza trocas culturais, existe a exposição ao risco. Kisliuk, ao compartilhar a sua experiência dividida entre estudantes da Universidade da Califórnia em Santa Bárbara e nativos da tribo Baaka, na República Africana Central, conclui que:

[...] as artes e a produção de conhecimento engajadas devem ser ao mesmo tempo enraizadas, ou seja, baseadas na comunidade e ativas nela e, conseqüentemente, arriscadas politicamente, intelectualmente e esteticamente. O desafio é criar contextos assim dentro de instituiçôes como as universidades, que por natureza são conservadoras e concebidas, em parte, para manter o status quo das estruturas de poder estaduais, nacionais e mundiais (Kisliuk, 2002, p. 116).

É imprescindível, aqui, lembrar Augusto Boal e sua longa jornada de riscos, perseguição e exílio, até conquistar o reconhecimento e sucesso internacional de que goza hoje. Talvez a principal razão para a aceitação mundial do Teatro de Oprimido seja, justamente, o alto grau de envolvimento que o método proporciona, voltado para o desenvolvimento da cidadania, da transformação do espectador comum em agente/ator de sua própria história em andamento. Num projeto de pesquisa, através dessa prática, pude conhecer o pensamento de meninas adolescentes marginalizadas, anônimas que vivem ou viveram nas ruas e, nesse ambiente, enfrentaram fome, frio, estupro, gravidez inde-

4 O espaço conquistado por Estudos da Performance na universidade brasileira ainda é tímido. Nos Estados Unidos, apesar de predominarem os cursos de teatro tradicional, percebe-se açóes de consolidação da área. Além da bem conhecida base na New York University (ver <www.performance. tisch.nyu.edu>), quero pontuar o exemplo da Northwestern, que estabeleceu departamentos autônomos de Performance e Teatro (ver <www.communication.northwestern.edu>) e exibe um currículo bem representativo do que Mckenzie denomina Performance Cultural. 
sejada, espancamentos, dor, exploração para narcotráfico, prostituição, crimes de homicídio e latrocínio e, finalmente, foram encarceradas. Através de jogos de Boal, numa oficina durante um semestre, elas puderam não só representar as suas biografias, mas identificar focos de opressão e vislumbrar caminhos para transformar suas vidas, sendo capazes de conceber performances dessa metamorfose. ${ }^{5}$

O Teatro do Oprimido tem afinidades com as práticas ritualísticas e grande potencial multiplicador. Num ritual autêntico, existe vivência e a repetição de uma tradição. As pessoas não vêm para observar, mas para participar e compartilhar. O ritual reforça uma tradição. Teatro e performance também podem servir para reforçar uma tradição e implicar a observação, mas são gêneros que operam com a convenção do "meta-comentário cultural e social", conforme observa Carlson (1996, p. 196). Assim, o teatro e a performance engajados têm em comum o desejo de intervenção e negociação cultural e política, não para manter tradiçōes, mas para contestar e rever a sociedade.

Cabe contemplar mais um pouco de Brasil. Süssekind afirmou que existe "um rastro de Guignol na vida cultural brasileira das últimas décadas" (2004, p. 16). A violência e o horror que, no final do século 18 , foram a base para a criação do boneco francês Guignol, de fato, continuam presentes em nossa produção artística. Não são apenas as letras de rap e funk que denunciam, criticam e/ou polemizam as doenças sociais. Proliferam na arte da performance, no teatro, na dança, no cinema, na literatura e nas artes visuais os trabalhos sobre abusos, homicí- dios, estupros e outras violências. O Théâtre $d u$ Grand Guignol, hoje tão distante dos cabarets da Paris do século 19, é o nome da vida de muitos adolescentes brasileiros. Os impactos da cultura de abuso e violência, apesar da existência de leis, são cada vez mais extensos. Diariamente, são divulgados folhetos, livros e documentários, publicados por órgãos governamentais e não governamentais especialmente direcionados aos vários tipos de injustiça social. São Conselhos Tutelares, Redes de Combate à Exploração Sexual Infanto-Juvenil, SOS Criança, etc.

Flora Süssekind escolheu bem, como sempre. Guignol é uma ótima-antiga-metáfora para captar o espírito da cena urbana atual. Nesse contexto, fazer uma performance engajada no combate a algum tipo de violência pode parecer o clichê "pingar uma gota d'água num oceano" turvo de fatos que aumentam, diariamente, a perplexidade de quem percebe a impunidade e o crescimento das práticas de abuso. Consideradas as eternas limitações da política cultural no Brasil, é apenas de gota em gota que todas as artes podem continuar contribuindo não só para pensar problemas sociais, mas para oferecer visóes alternativas a essas sombras Guignol.

Embora a visão canônica ainda persista no meio acadêmico, é senso comum que o campo da performance cultural, ao rejeitar as convenções de hierarquização e exclusão, criou espaços para que todas as pessoas, de qualquer comunidade, atuem estética e ideologicamente sobre a sociedade. ${ }^{6}$ Por outro lado, a maior tarefa dos estudos atuais da performance talvez seja esboçar uma metodologia eficaz para tratar da

5 Oficina realizada na Unidade Social Oficial Joana Miguel Richa, em Curitiba, no segundo semestre de 2003. Minha orientação e direção de performances para criação do roteiro cênico Sombras de Sycorax (Rauen, 2005).

6 Artigos e notícias disponíveis na Internet mostram o quanto se está produzindo. <www.findarticles. com> é um dos bancos representativos. A Brief Guide to Internet Resources in Theatre and Performance Studies é, no entanto, um recurso específico e atualizado sobre referências na Web (ver <www.stetson. edu/ $\sim$ csata/thr_guid.html>.) 
dimensão global e intercultural da performance, mesmo sendo irônico pensar em método para um campo cuja natureza é caótica. O estudo da performance cultural, apesar de suas vantagens, também propicia o reducionismo cultural e as visões compartimentalizadas da produção performática. O pensamento global e intercultural, ao contrário, seja para analisar a integração ou a disjunção, intensifica o relacionamento entre sistemas, comportamentos e estilos:

A performance intercultural precisa ser estudada junto com a globalização porque ela surge como reações e, em alguns casos, como protestos contra um mundo crescentemente integrado. Ambas, globalização e performance intercultural, têm antecedentes históricos. A globalização, no colonialismo e no imperialismo; a performance intercultural, enquanto resultado do 'contato' entre os povos do mundo. Claramente, esses fenômenos em si estão ligados (Schechner, 2002, p. 226).

Para complementar esse olhar, vale mencionar o princípio de que todo texto carregado da história de seu tempo, apesar das topicalidades e singularidades, pode ser relido ou transposto para outros contextos. Essa "iterabilidade [...] unicidade, identificação e alteração em repetição [...] é inerente à historicidade" (Derrida, 1992, p. 63).

Os seres humanos de todo o planeta ainda têm muito aprendizado pessoal a fazer, no sentido de ahimsa (do sânscrito - não-violência), de sua integração e de vivências para o intercâmbio e a paz. Um grande mestre brasileiro, Lama Padma Samten, ${ }^{7}$ inspirando-se no Dalai Lama, ensina o quanto é crucial agirmos para mudar as paisagens de violência que nos cercam.
Um primeiro passo nessa direção seria perceber a cultura da paz como um tema transversal em nosso cotidiano, reorganizando a nossa própria paisagem mental:

Quando o tema da cultura da paz se torna transversal a todas as atividades [...] Nós substituímos a questão de gostar ou não gostar por uma perspectiva mais elevada - todos os seres buscam a felicidade e buscam se afastar do sofrimento. [...] Mas quando falamos em felicidade, devemos compreende-la não apenas no nível individual, mas também nos outros três níveis: relacional, social e ambiental. Olhar para os outros níveis não significa que estejamos sendo bonzinhos [ou politicamente corretos, como dizem algumas pessoas]. O fato é que todos esses níveis estão presentes e operando. Se nós conseguirmos vincular todas as ações desses vários níveis a um eixo positivo, teremos encontrado um critério para verificar a qualidade de nossas ações e para mudar o que for necessário (apud Caruso, 2005, p. 30-1).

Em tempos de chamada para o encontro "Performance Studies International", que acontecerá na School of English and Drama Queen Mary, University of London (Psi\#12, 15-18 de junho de 2006) e depois de quase cem anos de engajamento, a performance política em sintonia com a cultura da paz parece estar ganhando momentum. A curadoria busca trabalhos ligados ao tema "Performing Rights: O que a performance pode fazer pelos direitos humanos e os direitos humanos pela performance?", considerando, entre outros tópicos, "o ativismo direcionado para a criação e a defesa de direitos humanos, a performance de protesto, revolução e

7 Alfredo Aveline, professor do Departamento de Física da UFRGS por 25 anos, foi ordenado Lama Padma Santen por seu mestre Chagdud Tulku Rinpoche, da linhagem tibetana Ningmapa, em 1996. Criou, preside e dirige o Centro de Estudos Budistas Bodisatva, na região rural de Viamão (RS) (ver $<$ www. bodisatva.org > ou <www.caminhodomeio.org >). 
insurreição, a ação direta não-violenta, [...] a performance de identidades que criem novos direitos políticos, [...] as performances do humano, da violência contra seres humanos e da capacidade humana de sofrer, [...] a liberdade de expressão e de informação" (ver <http://psiweb.org $>$ ). Esse compromisso formal da maior associação mundial de estudos de performance com as carências e doenças da sociedade e de suas guerras transcende as noções primárias de esquerda e direita, os discursos panfletários: é um desafio ético e um convite para o engajamento e a construção da cidadania muito além de quaisquer fronteiras. AHIMSA!

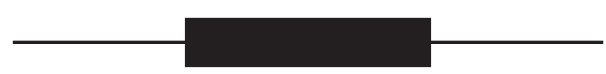

\section{Referências bibliográficas}

AUSLANDER, Philip. Presence and resistance: postmodernism and cultural politics in contemporary american performance. Ann Arbor: University of Michigan, 1994.

BERNSTEIN, Ana. "A casa com vista para o mar de Marina Abramovic'. Entrevista a Ana Bernstein". Sala Preta, 2003, n. 3, p. 132-40.

BOAL, Augusto. Teatro do oprimido e outras poéticas políticas. Rio de Janeiro: Civilização Brasileira, 1975.

. Teatro legislativo: versão beta. Rio de Janeiro: Civilização Brasileira, 1996.

CARLSON, Marvin. Performance, a critical introduction. London: Routledge, 1996.

CARUSO JR., Vitor. Mestres da cultura da paz. São Paulo: RiMa, 2005.

CHADWICK, Whitney. Women, art, and society. 2a. ed. London: Thames and Hudson, 1997.

COHEN, Renato. Performance como linguagem. São Paulo: Perspectiva, 1987.

. "Rito, tecnologia e novas mediações na cena contemporânea brasileira". Sala Preta, 2003, n. 3, p. 117-24.

COHEN-CRUZ, Jan (ed.). Radical street performance: an international anthology. London: Routledge, 1998.

COLLERAN, Jeanne \& SPENCER, Jenny S. (eds.). Staging resistance: essays on political theater. Ann Arbor: University of Michigan, 1998.

DENNING, Michael. "Teatro e política nos Estados Unidos da América”. In: DE CARVALHO, Sérgio (org.). O teatro e a cidade. São Paulo: SMC, 2004, p. 211-25.

DERRIDA, Jacques. Acts of literature. Ed. de Derek Attridge. New York/Londres: Routledge, 1992.

ELAM JR., Harry J. Taking it to the streets: the social protest theater of Luis Valdez \& Amiri Baraka. Ann Arbor: University of Michigan, 1997. 
GOLDBERG, Rose Lee. Performance art: from futurism to the present. New York: Harry N. Abrams, 1988.

GLUSBERG, Jorge. A arte da performance. Trad. de Renato Cohen. São Paulo: Perspectiva, 2003.

GRAY, John (org.). Action art. A bibliography of artists' performance from futurism to fluxus and beyond. Westport/London: Greenwood, 1993.

GROSENICK, Uta. Women artists in the 20th and 21st century. Köln/London: Taschen, 2001.

KISLIUK, Michelle. "The poetics and politics of practice. Experience, embodiment, and the engagement of scholarship". In: STUCKY, Nathan \& WIMMER, Cynthia (eds.). Teaching performance studies. Carbondale/Edwardsville: Southern Illinois Press, 2002, p. 99-117.

LOEFFLER, Carl E. \& TONG, Darlene (eds.). Performance anthology. San Francisco: Contemporary Arts Press, 1980.

MCKENZIE, Jon. Perform or else. From discipline to performance. London: Routledge, 2001.

MONTANO, Linda M. Performance artists talking in the eighties: sex, food, money/fame, ritual/death. Berkeley: University of California Press, 2000.

RAUEN, Margarida G. "Do problema social à performance”. In: DIAB MALUF, Sheila \& DE AQUINO, Ricardo Bigi. Reflexóes sobre a cena. Maceió/Salvador: EDUFAL/EDUFBA, 2005, p. 233-45.

REINELT, Janelle G. \& ROACH, Joseph R. (eds.). Critical theory and performance. Ann Arbor: The University of Michigan Press, 1992.

SCHECHNER, Richard. Performance theory. New York/London: Routledge, 1988.

Performance studies: an introduction. London/New York: Routledge, 2002.

SÜSSEKIND, Flora. "Desterritorialização e forma literária”. Sala Preta, 2004, n. 4, p. 11-29. 